УДК 616-053.5-084:613.955

ОЗДОРОВЛЕНИЕ ДЕТЕЙ В ЛЕТНИХ ОЗДОРОВИТЕЛЬНЫХ УЧРЕЖДЕНИЯХ АСТРАХАНСКОЙ ОБЛАСТИ

\author{
Сибирякова Н.В., Агого Э. \\ ФГБОУ ВО Астраханский ГМУ Минздрава России, \\ Астрахань, Россия
}

\title{
IMPROVING THE HEALTH OF CHILDREN IN SUMMER HEALTH-IMPROVING INSTITUTIONS OF THE ASTRAKHAN REGION
}

\author{
Sibiryakova N.V., Agogho E. \\ Astrakhan State Medical University, \\ Russia, Astrakchan
}

\begin{abstract}
Аннотация. Одной из актуальных проблем медицины и образования является вопрос отдыха и оздоровления детского населения, в том числе и в летнее, каникулярное время. Летний период - один из важных этапов отдыха и оздоровления детей и подростков, когда существует возможность охватить системой оздоровительных мероприятий наибольшее количество учащихся. Для оценки эффективности оздоровления изучались в динамики показатели: рост, масса тела, мышечная сила рук и жизненная емкость легких. По результатам проведенного исследования, проведенных в начале и в конце смены, суммарная эффективность оздоровления составляет: выраженный оздоровительный эффект - 210 (90,1\%), слабый оздоровительный эффект - 23 (9,9\%), отсутствие оздоровительного эффекта - 0\%. Таким образом, изучение оздоровление, укрепление здоровья детей во взаимосвязи с факторами среды обитания позволяет повысить эффективность мероприятий, направленных на улучшение качества среды обитания и здоровья подрастающего поколения.

Annotation. One of the urgent problems of medicine and education is the issue of recreation and health improvement of the children's population, including in the summer, vacation time. The summer period is one of the important stages of recreation and recreation for children and adolescents, when it is possible to cover the largest number of students with a system of recreational activities. To assess the effectiveness of health improvement, the following indicators were studied in dynamics: height, body weight, arm muscle strength and lung vital capacity. According to the results of the study conducted at the beginning and at the end of the shift, the total effectiveness of recovery is: pronounced health effect $210(90.1 \%)$, weak health effect $-23(9.9 \%)$, no health effect $-0 \%$. Thus, the study of the improvement and strengthening of children's health in connection with environmental factors makes it possible to increase the effectiveness of measures aimed at improving the quality of the environment and the health of the younger generation.
\end{abstract}

Ключевые слова: дети, здоровье, летний оздоровительный лагерь, оздоровительные мероприятия.

Key words: children, health, summer health camp, wellness activities.

Актуальность. В условиях современного изучения проблемы сохранение и укрепление здоровья школьников становятся все более актуальными. Ухудшение качества жизни, негативное воздействие на здоровье социальных, экономических, экологических и психологических факторов снижают уровень устойчивости организма.

Отдых и оздоровление детей - совокупность мероприятий, обеспечивающих развитие творческого и интеллектуального потенциала, охрану и укрепление физического и психического здоровья, профилактику заболеваний, занятие их физической культурой, спортом, формирование навыков здорового образа жизни, соблюдение рационального и сбалансированного питания, режима дня, закаливание и жизнедеятельности в благоприятной окружающей среде $[1,2,3,4,5,6,8,9]$.

Цель исследования: оценка эффективности оздоровления детей и подростков в оздоровительном лагере.

Материалы и методы. Объектом исследования были дети в возрасте 7-15 лет, находившиеся на период отдыха и оздоровления в детском оздоровительном лагере «Юный железнодорожник» - Астраханская область. Общее количество детей составило 233. Дети были расформированы на семь отрядов в зависимости от возраста. Прием детей осуществлялся при наличии заключения врача об отсутствии контактов с инфекционными больными, о состоянии здоровья детей и сведений об имеющихся прививках. Одновременно с осмотром проводился анализ развития детей и их заболеваемости по данным индивидуальных медицинских карт школьника. 
С помощью стандартных методик изучались следующие показатели: рост, масса, мышечная сила кистей. Функциональные показатели дыхания оценивались посредством измерения ЖЕЛ (жизненная емкость легких) спирометром СП-01.

Ежедневно проводились общеоздоровительные мероприятия: закаливание (воздушные и солнечные ванны, обтирание, обливание, душ, купание), комплекс физических упражнений. Питание детей пятиразовое. Особое внимание обращали на достаточную витаминизацию пищи и увеличивали ее за счет дополнительного введения в рацион свежих овощей и фруктов.

Результаты и их обсуждение. По состоянию здоровья дети распределялись на пять групп: I - 126/54,1\%, II - 82/35,2\%, III - 25/10,7\%. Дети IV и V группы здоровья не было. По результатам антропометрических данных к концу смены увеличилась масса тела у детей распределенных по следующим группам здоровья: I - 10/23,3\%, II 20/46,5\%, III - 13/30,2\%. По результатам антропометрических данных к концу смены уменьшилась масса тела у детей, в том числе у четверых детей, имеющего повышенную массу тела (дисгармоничное физическое развитие), распределенных по следующим группам здоровья в виду занятия подвижными играми, повышенной температуры воздуха и снижение аппетита у данной категории детей: I - 2/9,1\%, II - 12/54,5\%, III - 8/36,4\%.

Одним из основных критериев оценки состояния здоровья детского населения является уровень его заболеваемости. Анализ полученных данных показал, что у детей наиболее представительными являлись заболеваний органов зрения $(28,8 \%)$ и нервной системы $(23,1 \%)$.

Результаты проведенного анализа показали, что ЖЕЛ у детей І группы были достоверно выше, чем у детей II и III групп, а показатели во II группе аналогично выше, чем в III. Это, в частности, обусловлено разницей в физическом развитии детей данных групп.

На основании антропометрических и физиологических данных медицинского осмотра, проведенных в начале и в конце (рост, вес, ЖЕЛ, динамометрия), суммарная эффективность оздоровления составляет: выраженный оздоровительный эффект - 210 (90,1\%), слабый оздоровительный эффект - 23 (9,9\%), отсутствие оздоровительного эффекта - 0\% [7].

Заключение. Таким образом, изучение оздоровление, укрепление здоровья детей во взаимосвязи с факторами среды обитания позволяет повысить эффективность мероприятий, направленных на улучшение качества среды обитания и здоровья подрастающего поколения.

\section{ЛИТЕРАТУРА}

1. Антонова А.А., Давыденко Д.В., Яманова Г.А. Мониторинг оздоровления детей и подростков в летний период отдыха // Новая наука: Опыт, традиции, инновации. - 2016. - № 11-2. - С.21-23.

2. Антонова А.А., Сердюков В.Г., Яманова Г.А. Влияние отдыха в летнем детском оздоровительном лагере на организм ребенка // В сборнике: XVI МЕЖДУНАРОДНЫЕ НАУЧНЫЕ ЧТЕНИЯ (ПАМЯТИ ШУВАЛОВА И.И.). сборник статей Международной научно-практической $\quad$ конференции. - $2017 . \quad$ C.140-142.

3. Антонова А.А., Сердюков В.Г. Отдых и оздоровление детей и подростков в летних оздоровительных учреждениях Астраханской области // В сборнике: Современные проблемы развития фундаментальных и прикладных наук. Материалы III международной научно-практической конференции. - 2016. - С.11-16.

4. Антонова А.А., Хуторская Т.А. Состояние здоровья физического развития детей дошкольного возраста // Международный научно-исследовательский журнал. - 2020. - № 11 (101). - Часть 2. - С.10 -13.

5. Антонова А.А., Яманова Г.А., Давыденко Д.В. Гигиенические особенности внешнего дыхания у детей // Новая наука: Опыт, традиции, инновации. - 2016. - № 11-2. - С.20-21.

6. Елизарова И.С., Сердюков В.Г., Антонова А.А. Мониторинг состояния здоровья школьников 6-15 лет в Астрахани // Астраханский медицинский журнал. - 2011. - Т. 6. - №3. - С.285-287.

7. Методические рекомендации МР 2.4.4.0127-18 «Методика оценки эффективности оздоровления в стационарных организациях отдыха и оздоровления детей». Утверждены Главным государственным санитарным врачом РФ 11 мая 2018 г.

8. Танина Н.А., Иорданская Н.А., Поздеева Т.В. Эффективность оздоровления детей и подростков в летнем загородном учреждении // Медицинский альманах. - 2013. - №6(30). - С.159-161.

9. Яманова Г.А., Сердюков В.Г., Антонова А.А., Милюченкова Л.А., Ширинова 3.Р. Эффективность мониторинга и оздоровления детского населения в образовательной среде // Вестник ВолгГМУ. - №1 (77). - 2021. - C.173-177.

10. Яманова Г.А., Сердюков В.Г., Антонова А.А. Оценка динамики показателей физического развития кадетов // В сборнике: ПРОФИЛАКТИЧЕСКАЯ МЕДИЦИНА - 2017. сборник научных трудов Всероссийской научно-практической конференции с международным участием. - 2017. - С.312-316.

\section{References}

1. Antonova A.A., Davydenko D.V., Yamanova G.A. Monitoring ozdorovleniya detey i podrostkov v letniy period otdykha // Novaya nauka: Opyt, traditsii, innovatsii. - 2016. - № 11-2. - pp.21-23. (In Russian). 
2. Antonova A.A., Serdyukov V.G., Yamanova G.A. Vliyanie otdykha v letnem detskom ozdorovitel'nom lagere na organizm rebenka // V sbornike: XVI MEZhDUNARODNYE NAUChNYE ChTENIYa (PAMYaTI ShUVALOVA I.I.). sbornik statey Mezhdunarodnoy nauchno-prakticheskoy konferentsii. - $2017 . \quad$ - pp.140-142. (In Russian).

3. Antonova A.A., Serdyukov V.G. Otdykh i ozdorovlenie detey i podrostkov v letnikh ozdorovitel'nykh uchrezhdeniyakh Astrakhanskoy oblasti // V sbornike: Sovremennye problemy razvitiya fundamental'nykh i prikladnykh nauk. Materialy III mezhdunarodnoy nauchno-prakticheskoy konferentsii. - 2016. - pp.11-16. (In Russian).

4. Antonova A.A., Khutorskaya T.A. Sostoyanie zdorov'ya fizicheskogo razvitiya detey doshkol'nogo vozrasta // Mezhdunarodnyy nauchno-issledovatel'skiy zhurnal. - 2020. - № 11 (101). - Chast' 2. - pp.10 -13. (In Russian).

5. Antonova A.A., Yamanova G.A., Davydenko D.V. Gigienicheskie osobennosti vneshnego dykhaniya u detey // Novaya nauka: Opyt, traditsii, innovatsii. - 2016. - № 11-2. - pp.20-21. (In Russian).

6. Elizarova I.S., Serdyukov V.G., Antonova A.A. Monitoring sostoyaniya zdorov'ya shkol'nikov 6-15 let v Astrakhani // Astrakhanskiy meditsinskiy zhurnal. - 2011. - T. 6. - №3. - pp.285-287. (In Russian).

7. Metodicheskie rekomendatsii MR 2.4.4.0127-18 «Metodika otsenki effektivnosti ozdorovleniya v statsionarnykh organizatsiyakh otdykha i ozdorovleniya detey». Utverzhdeny Glavnym gosudarstvennym sanitarnym vrachom RF 11 maya 2018 g. (In Russian).

8. Tanina N.A., Iordanskaya N.A., Pozdeeva T.V. Effektivnost' ozdorovleniya detey i podrostkov v letnem zagorodnom uchrezhdenii // Meditsinskiy al'manakh. - 2013. - №6(30). - pp.159-161. (In Russian).

9. Yamanova G.A., Serdyukov V.G., Antonova A.A., Milyuchenkova L.A., Shirinova Z.R. Effektivnost' monitoringa i ozdorovleniya detskogo naseleniya v obrazovatel'noy srede // Vestnik VolgGMU. - №l (77). - 2021. pp.173-177. (In Russian).

10. Yamanova G.A., Serdyukov V.G., Antonova A.A. Otsenka dinamiki pokazateley fizicheskogo razvitiya kadetov // V sbornike: PROFILAKTIChESKAYa MEDITsINA - 2017. sbornik nauchnykh trudov Vserossiyskoy nauchnoprakticheskoy konferentsii s mezhdunarodnym uchastiem. - 2017. - pp.312-316. (In Russian). 